\title{
Applying recent insights from climate risk management to operationalize the Loss and Damage Mechanism
}

\author{
Thomas Schinko1,2, ${ }^{1}$ Reinhard Mechler ${ }^{1,3}$
}

Final author version of:

Schinko, T. and Mechler, R. (2017). Applying Recent Insights From Climate Risk Management to Operationalize the Loss and Damage Mechanism. Ecological Economics: 13. DOI:10.1016/j.ecolecon.2017.02.008. (In Press)

\begin{abstract}
:
With the impacts of climate change already being felt across the globe, it is imperative to manage and avoid further irreversible loss and intolerable damage. Adaptive learning, linked to climate risk management (CRM) and building on principled socio-economic analysis, can help overcome substantial scientific and political challenges, and provide operational support for debate around the Warsaw International Mechanism (WIM) for Loss and Damage (L\&D).
\end{abstract}

${ }_{1}$ International Institute for Applied Systems Analysis (IIASA)

2 Wegener Center for Climate and Global Change, University of Graz

3 Vienna University of Economics and Business

* Corresponding author: International Institute for Applied Systems Analysis (IIASA), Schlossplatz 1, A 2361

Laxenburg, Austria. E-mail address: schinko@iiasa.ac.at; Phone: +43223671313 


\section{Introduction}

It is indisputable that the most significant and welcome outcome of the $21^{\text {st }}$ Conference of the Parties to the Climate Convention (COP 21) in Paris was the agreement on the ambitious target of limiting global warming to "well below $2^{\circ} \mathrm{C}$ " temperature, with efforts of further reducing this to $1.5^{\circ} \mathrm{C}$. The announcement of the Paris Agreement generated intense discussions regarding the scientific challenges ahead ${ }^{2,3}$ as well as concerning the political and technical feasibility of the target. Despite the Paris Agreement's call for a "global [peak] in greenhouse gas emissions as soon as possible ... and [the undertaking of] rapid reductions thereafter", current GHG emission reduction pledges and mitigation efforts are likely to lead to significantly higher levels of warming 4 , thus intensifying what are already significant impacts on the climate world-wides.

Policy makers, practitioners and members of civil society are increasingly advocating to pursue a climate risk management strategy, i.e. comprehensively managing existing and future climaterelated risks, including to limit their adverse impacts on natural structure and functioning of ecosystems, and the ability of countries to pursue sustainable development pathways. ${ }^{6}$ This imperative becomes particularly challenging when focusing on those impacts that cannot or will not be avoided through mitigation and adaptation, thus causing irreversible loss and residual damage, which can be alleviated to some extent 7 ; this is particularly true for the global South where coping capacities for climate variability are often already strained due to a number of trends unrelated to climate change ${ }^{8}$.

Seen from this perspective, another important outcome of COP 21 was the full endorsement of the WIM. Its historical roots date back to a 1991 proposal by the Alliance of Small Island States (AOSIS), arguing for the establishment of an international insurance pool serving a collective loss-sharing scheme to compensate the most vulnerable small island and low-lying coastal developing countries for loss and damage. ${ }^{9}$ Following intense debate over the following two decades, the WIM was institutionalized in 2013 at COP 19 in Warsaw (decision 2/CP.19) "to address loss and damage associated with impacts of climate change, including extreme events and slow onset events, in developing countries that are particularly vulnerable to the adverse effects of climate change"10. An Executive Committee has been established to further the development of a policy framework for L\&D under the UNFCCC, however the concrete scope and scale for L\&D remains (deliberately) unclear in the climate policy discourse ${ }^{11}$. While the parties to the UNFCCC acknowledge that L\&D "includes, and in some cases involves more than, that which can be reduced by adaptation" and some authors argue that it focuses on those climate-related risks where physical and socio- 
economic limits to adaptation are breached ${ }^{12}$, the boundaries between climate change adaptation (CCA) and L\&D, and thus the WIM's remit has been unclearly defined. This remains a core issue even as the WIM has very generally been reviewed at COP 22 in Marrakesh in November 2016, with a closer scrutiny scheduled for 2019.

At the same time, finding common ground among non-Annex I countries demanding compensation for incurred losses, and Annex I countries suggesting to focus on risk management of future losses seems possible. Mechler and Schinko recently pointed out a policy space for L\&D with two sets of options as distinct from CCA or disaster risk reduction (DRR). ${ }^{13}$ The first set of options refers to support for curative measures, which deal with unavoided and unavoidable risks. The second set of options refers to the concept of transformative risk management-that means building resilience against climate-related impacts while also realizing that people and communities will need support to develop new livelihoods, or even voluntarily migrate to new homes to cope with the impacts of climate change.

Identifying the L\&D risk and policy space appears useful to ensure that support, including funding, from the WIM is aimed at those countries in greatest need. Yet, the question remains how to implement action on climate-related risks today and in the future given a number of risk-analytical and socio-political challenges. We summarize these challenges before presenting a framework building on adaptive learning theory as applied to climate change via the concept of iterative CRM, which holds great potential for addressing the remit of L\&D. As we will argue in more detail below, we see the main advantage of this approach in that it provides an immediate strategy for tackling the climate crisis ${ }^{14}$-early action on climate change considered highly relevant for the prevention and management of climate change impacts, in addition to establishing transformative adaptation and mitigation pathways and ultimately limiting global warming to $1.5^{\circ} \mathrm{C}$ vs $2^{\circ} \mathrm{C}^{15}$.

\section{Challenges associated with operationalizing the Loss and Damage Mechanism}

Several major challenges are inherent to the evaluation of alternatives within the L\&D field. First, the large uncertainty regarding potential future impacts of climate change at global, regional and local levels has to be acknowledged. Uncertainties accumulate along a cascade, beginning with input data to climate models; this may include emission scenarios which depend on assumptions about demographic and socioeconomic development, global climate model results, regional climate model or downscaling results, and how natural and social systems will respond to climate impacts (comprising sudden-onset extreme events, such as floods, and gradual slow-onset processes, such as rising sea levels and acidification of the oceans) ${ }^{16}$. Second, the attribution of loss and damage 
from specific climate-related disasters to climate change is not yet conclusive. So far, the rise in losses has been primarily attributed to socioeconomic trends and increased exposure of people and capital to risk; at the same time, however, the influence of climate change on trends in losses cannot be excluded ${ }^{17}$. Third, climate-related impacts - positive as well as negative - are likely to be distributed unequally across nations and generations, leading to salient questions regarding distributive and compensatory justice ${ }^{18}$. Fourth, while economic loss and damage linked to climaterelated disasters is of immediate importance, there is further loss and damage that is not commonly traded in the market and that cannot be readily offset by compensation or redistribution of material goods. This class of L\&D has entered the L\&D discourse as the concept of non- economic loss and damage (NELD) or after COP21 in Paris, non-economic losses (NELs) (e.g. impacts on ecosystems, health, security, biodiversity, and loss of cultural identity) ${ }^{19}$. Fifth, L\&D is a highly politicized and normatively laden topic, with a broad range of stakeholders; climate negotiators, civil society, disaster risk management practitioners, researchers from different disciplines, and the private sector (foremost insurance and reinsurance companies) are all involved in the discourse and, while doing so, pursuing their respective agendas.

Conventional economic approaches, methods and tools, such as benefit-cost analysis and expected utility theory, are not well-equipped to tackle these methodological challenges, particularly as their capacity to deal with risk and uncertainty ${ }^{20}$, as well as with distributional effects and non-market impacts, is rather limited.

\section{From disaster risk reduction, via adaptation, to climate risk management}

There is a long history of managing climate-related and geophysical-driven extremes via DRR. The IPCC's SREX ${ }^{21}$ and $5^{\text {th }}$ assessment reports ${ }^{22}$ identified numerous synergies between DRR and CCA and called for further linking of agendas under the umbrella of CRM. By concurrently tackling DRR and CCA, CRM may serve as a blueprint for early action on climate-related risks-gaining experience through linking climate-relevant science to decision making on the current adaptation deficit (existing climate variability and extremes) for mainstreaming climate change into mediumterm CRM. In particular, CRM stands for comprehensively reducing, preparing for, and financing climate-related risk, while tackling the underlying risk drivers, including climate-related and socioeconomic factors ${ }^{23}$ - potentially yielding important dividends while increasing resilience ${ }^{24}$.

By building on recent methodological developments in climate risk analysis and management 25 , a framework emerges to tackle the challenges outlined above. The underlying CRM framework has been developed and applied in a national decision context focusing on flood risk. Despite 
considerable uncertainties in establishing a strong causal link to anthropogenic climate change as risk driver, employing climate-relevant science to decision making on existing short-term risks has proven useful to inform instrumental as well as reflexive and participatory debate in practice. Given similar challenges in attribution science at a global level as outlined above, we deem an approach based on a CRM framework, comprising multiple methods and tools, and embedded in a comprehensive participatory process at all stages, capable of supporting the operationalization of the WIM.

\section{Applying lessons learnt from CRM to the WIM}

We conceptualize a transdisciplinary dynamic framework (Figure 1) based on these recent findings to comprehensively address climate-related risk - from hazard to risk analysis, accounting for underlying socio-economic and climate-related drivers, as well as for different stakeholder perceptions. By linking this framework to theories of learning under risk and uncertainty ${ }^{26}$ and the IPCC's 'reasons for concerns' framework (representing the conceptual framing of climate risk under the UNFCCC as dangerous anthropogenic interference with the climate system) ${ }^{27}$, it is possible to establish iterative and transformative approaches to comprehensively address climate-related risk. Approaches such as these allow for the dynamic updating of L\&D practice as climate risk increases and new knowledge on the complex dynamics of social-ecological systems and their interactions with a changing climate becomes available.

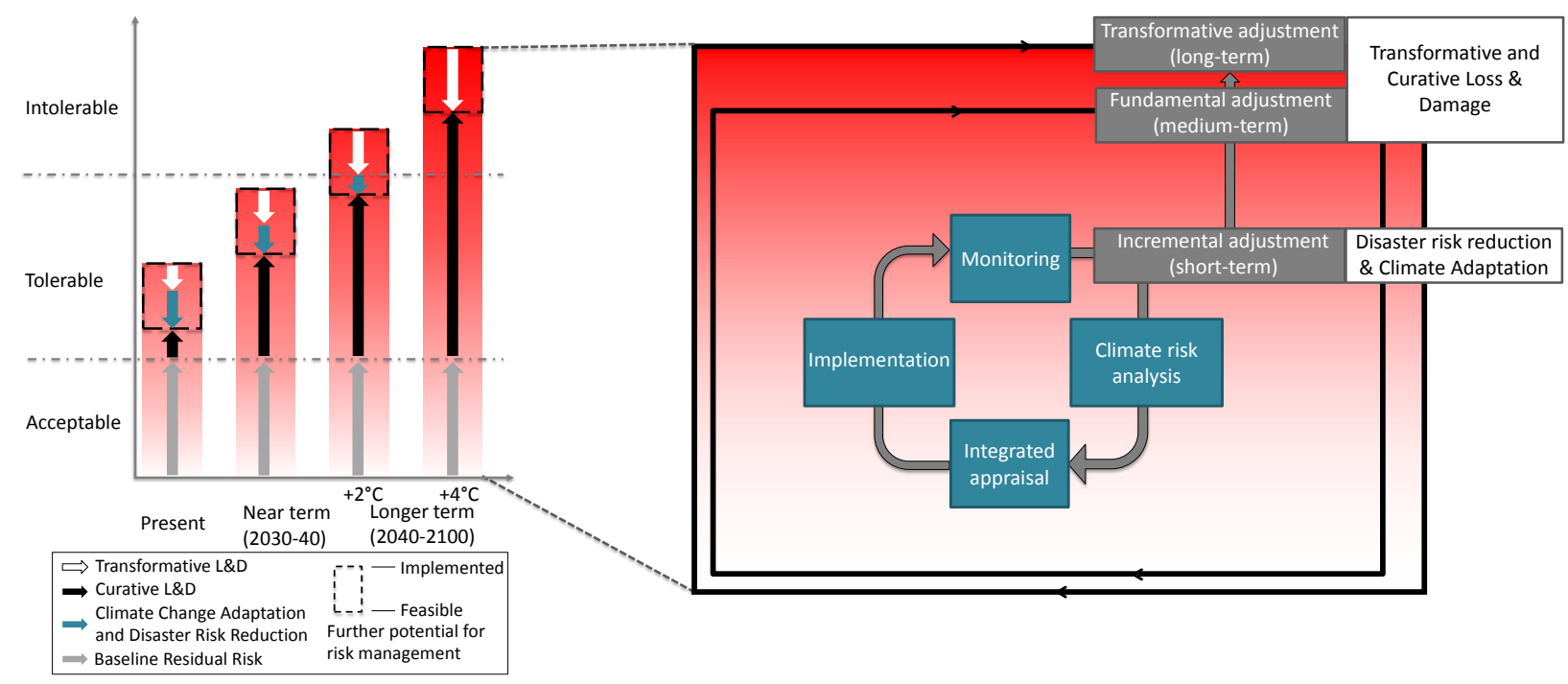

Figure 1: Dynamic framework for assessing and managing climate-related risks. On the left, climate-related risks according to IPCC's regional assessment illustrating the levels of risk and risk tolerance with color shading (here for the case of small-island states). The dashed boxes depict the part of risk that can be 
managed either by conventional CCA and DRR (blue-green arrows) or novel transformative L\&D measures (white arrows), the black arrows the part for which curative L\&D measures have to be set in place. On the right, a framework to tackle increasing climate-related risks. In the short term the incremental adjustment process consists of the following elements: Step (1): monitoring existing instruments, new scientific evidence on climate change, natural hazard data, loss databases, the climate signal, and stakeholder perceptions. Step (2): model-based analysis of climate-related sudden-onset risks and slow-onset processes, acknowledging the uncertainties associated with climate change. Step (3): integrated appraisal of the new normal and modeling results according to public and private coping capacities, taking into account economic L\&D, NELD and justice considerations. Step (4) Implementation or update of risk management instruments according to different layers of risk; this requires decision criteria under uncertainty (e.g. robust decision-making) and keeping in mind multiple dividends. The embedding in a learning loop framework allows for fundamental and transformative adjustments of the current reactive risk management processes, as well as mental and analytical models in the medium to long-term. Source: Own figure, Based on Mechler\&Schinko (2016), Schinko et al (2016) and IPCC (2014).

By addressing existing climate variability and extreme weather events in the short term, a CRMtype framework for L\&D could kick-start the operationalization of the WIM and circumvent a stalemate in the political process; given the current attribution challenges noted above, interminable discussions on the contribution of anthropogenic climate change to climate-related risks are doomed to continue. At the same time, by dynamically mainstreaming climate change into the L\&D practice as new scientific evidence emerges, the anthropogenic component in increasing climate-related risks will not be neglected in the medium to long-term; this sends a powerful message back to policy-makers in the mitigation domain to work together in order to meet the ambitious temperature targets.

\section{Acknowledgements:}

We thank Saskia Read for proof reading the article.

\section{Funding:}

This work received funding support from the project ENHANCE (Enhancing Risk Management Partnerships for Catastrophic Natural Disasters in Europe) funded by the European Commission under the Seventh Framework Programme (grant agreement no. 308438), as well as from the Zurich Flood Resilience Alliance. 


\footnotetext{
${ }^{1}$ Adoption of the Paris Agreement FCCC/CP/2015/L.9/Rev1 (United Nations Framework Convention on Climate Change, 2015).

2 Peters, G. (2016). The best available science to inform $1.5^{\circ} \mathrm{C}$ policy choices. Nature Clim Change http://dx.doi.org/10.1038/nclimate3000.

${ }^{3}$ Mitchel, D., James, R., Foster, P.M., Betts, R.A., Shiogama, H., Allen, M. (2016). Realizing the impacts of a $1.5{ }^{\circ} \mathrm{C}$ warmer world. Nature Clim Change

${ }^{4}$ Rogelj, J., den Elzen, M., Höhne, M., Franzen, T., Fekete, H., Winkler, H., Schaeffer, R., Sha, F., Riahi, K. and Meinshausen, M. (2016). Paris Agreement climate proposals need a boost to keep warming well below $2^{\circ} \mathrm{C}$. Nature, 534. pp. 631-639.

${ }^{5}$ IPCC Climate Change 2014: Impacts, Adaptation, and Vulnerability (eds Field, C.B. et al.) (Cambridge Univ. Press, 2014).

${ }^{6}$ IPCC (2014). Summary for policymakers. In: Climate Change 2014: Impacts, Adaptation, and Vulnerability. Part A: Global and Sectoral Aspects. Contribution of Working Group II to the Fifth Assessment Report of the Intergovernmental Panel on Climate Change [Field, C.B., V.R. Barros, D.J. Dokken, K.J. Mach, M.D. Mastrandrea, T.E. Bilir, M. Chatterjee, K.L. Ebi, Y.O. Estrada, R.C. Genova, B. Girma, E.S. Kissel, A.N. Levy, S. MacCracken, P.R. Mastrandrea, and L.L. White (eds.)]. Cambridge University Press, Cambridge, United Kingdom and New York, NY, USA, pp. 1-32.

${ }^{7}$ Felgenhauer (2015). Addressing the limits to adaptation across four systems. Environmental Science \& Policy 50:214-224.

${ }^{8}$ Abeygunawardena, Piya; Vyas, Yogesh; Knill, Philipp; Foy, Tim; Harrold, Melissa; Steele, Paul; Tanner, Thomas; Hirsch, Danielle; Oosterman, Maresa; Rooimans, Jaap; Debois, Marc; Lamin, Maria; Liptow, Holger; Mausolf, Elisabeth; Verheyen, Roda; Agrawala, Shardul; Caspary, Georg; Paris, Ramy; Kashyap, Arun; Sharma, Arun; Mathur, Ajay; Sharma, Mahesh; Sperling, Frank. 2009. Poverty and climate change: reducing the vulnerability of the poor through adaptation. Washington, DC: World Bank. http://documents.worldbank.org/curated/en/2009/01/11522293/poverty-climate-change-reducing-vulnerabilitypoor-through-adaptation

${ }^{9}$ Mace, M J and Roda Verheyen (2016). "Loss, Damage and Responsibility after COP21: All Options Open for the Paris Agreement". Review of European Community \& International Environmental Law 23(2):197-214. doi: 10.1111/reel.12172

${ }^{10}$ UNFCCC Decision 2/CP.19 (UNFCCC, 2013).

${ }^{11}$ James, R. et al. (2014). Characterizing loss and damage from climate change. Nature Clim. Change 4:938-939 (2014). Doi:10.1038/nclimate2411

${ }^{12}$ Verheyen, R. Tackling Loss \& Damage -A New Role for the Climate Regime? (Climate and Development Knowledge Network, 2012).

${ }^{13}$ Mechler, R. and T. Schinko (2016). Identifying the policy space for climate loss and damage. Science 354: 290-

292.

${ }^{14}$ Watkiss P, Hunt A, Savage M (2014). Early value-for-money adaptation: delivering VfM adaptation using iterative frameworks and low-regret options. Report by Global Climate Adaptation Partnership (GCAP) for evidence on demand

${ }^{15}$ Knutti et al. (2015). A scientific critique of the two-degree climate change target. Nature Geoscience 9:13-18. DOI: 10.1038/NGEO2595

${ }^{16}$ Kunreuther et al. (2013). Risk management and climate change. Nature Clim. Change3:447-450. DOI: 10.1038/NCLIMATE1740

${ }^{17}$ Verheyen (2015). Loss and damage due to climate change: attribution and causation - where climate science and law meet. Int. J. Global Warming 8(2):158-169. Doi: http://dx.doi.org/10.1504/IJGW.2015.071968

${ }^{18}$ Wallimann-Helmer, I. (2015). Justice for climate loss and damage. Clim Change 133:469-480. Doi:10.1007/s10584-015-1441-z

${ }^{19}$ Serdeczny, O., Waters, E., \& Chan, S. (2016). Non-Economic Loss and Damage in the Context of Climate Change. Bonn: German Development Institute/Deutsches Institut for Entwicklungspolitik. Discussion Paper.

http://www.die-gdi.de/uploads/media/DP 3.2016.pdf
} 
${ }^{20}$ Kunreuther et al. (2013). Risk management and climate change. Nature Clim. Change3:447-450. DOI: 10.1038/NCLIMATE1740

${ }^{21}$ IPCC (2012) Managing the risks of extreme events and disasters to advance climate change adaptation. A Special Report of Working Groups I and II of the Intergovernmental Panel on Climate Change. In: Field CB, Barros V, Stocker TF, Qin D, Dokken DJ, Ebi KL, Mastrandrea MD, Mach KJ, Plattner GK, Allen SK, Tignor M, Midgley PM (eds). Cambridge University Press, Cambridge and New York, p 582

22 Jones, R. et al. Foundations for decision making, 195-228 (IPCC, 2014).

${ }^{23}$ Mechler, R., Bouwer, L.M., Linnerooth-Bayer, J., Hochrainer-Stigler, S., Aerts, J.C.J.H., Surminski, S., Williges, K. (2014). Managing unnatural disaster risk from climate extremes. Nat Clim Change 4(4):235-237. doi:10.1038/ nclimate2137

${ }^{24}$ Surminski, S., Tanner, T. (eds.) (forthcoming). Realising the 'Triple Dividend of Resilience'. Springer. ISBN 978-3319-40694-7

${ }^{25}$ Schinko, T., Mechler, R., Hochrainer-Stigler, S. (2016). A methodological framework to operationalize Climate Risk Management: Managing sovereign climate-related extreme event risk in Austria. Mitigation and Adaptation Strategies for Global Change. DOI 10.1007/s11027-016-9713-0

${ }^{26}$ Lavell A, Oppenheimer M, Diop C, Hess J, Lempert R, Li R, Muir-Wood R, Myeong S (2012) Climate change: new dimensions in disaster risk, exposure, vulnerability, and resilience. In: Field CB, Barros V, Stocker TF, Qin D, Dokken DJ, Ebi KL, Mastrandrea MD, Mach KJ, Plattner GK, Allen SK, Tignor M, Midgley PM (eds) Managing the risks of extreme events and disasters to advance climate change adaptation, A Special Report of Working Groups I and II of the Intergovernmental Panel on Climate Change (IPCC). Cambridge University Press, Cambridge and New York, pp 25-64

${ }^{27}$ IPCC (2014). Summary for policymakers. In: Climate Change 2014: Impacts, Adaptation, and Vulnerability. Part A: Global and Sectoral Aspects. Contribution of Working Group II to the Fifth Assessment Report of the Intergovernmental Panel on Climate Change [Field, C.B., V.R. Barros, D.J. Dokken, K.J. Mach, M.D. Mastrandrea, T.E. Bilir, M. Chatterjee, K.L. Ebi, Y.O. Estrada, R.C. Genova, B. Girma, E.S. Kissel, A.N. Levy, S. MacCracken, P.R. Mastrandrea, and L.L. White (eds.)]. Cambridge University Press, Cambridge, United Kingdom and New York, NY, USA, pp. 1-32. 